\title{
POLICRONICIDADE E A SAÚDE DE ENFERMEIRAS (OS) QUE TRABALHAM EM HOSPITAL: ESTUDO DES- CRITIVO'
}

\section{Audrey Vidal Pereira²}

Resumo: Objetivo: analisar em que medida as experiências de policronicidade afetam a saúde de enfermeiras(os) que trabalham em hospital. Método: estudo descritivo com abordagem qualitativa. $O$ registro dos tempos diários foi computado por 42 enfermeiras(os) que viviam na região metropolitana do Estado do Rio de Janeiro - Brasil. A análise temática viabilizou que as informações fossem refletidas através de conceitos como policronia e monocronia. Resultados e Discussão: as enfermeiras têm uma tendência de naturalizar e consentir a vivência de policronicidade e os enfermeiros de negar e resistir. Conclusão: estudo aponta que as enfermeiras ao associarem as experiências de policronicidade à presença de filhos, aos cuidados de idosos e à execução de atividades domésticas, remetem às desigualdades de gênero cuja desorganização do tempo afeta de modo desproporcional a saúde das mesmas. Para realizar comparações específicas e possíveis generalizações existe a necessidade de futuras e ampliadas investigações.

Palavras-chave: usos do tempo; policronicidade; saúde; enfermeiras; enfermeiros.

Abstract: Objective: analyze if the experiences of polychronicity affect the health of nurses and nurses working in hospital. Method: descriptive study wich a qualititative approach. The daily time record was computed by 42 nurses living in the metropolitan region of the State of Rio de Janeiro - Brazil. Thematic analysis enabled the information to be reflected through concepts such as polychrony and monocrony. Results and discussion: the nurses have a tendency to naturalize and allow the carrying out of several activities at the same time and the men nurses to deny and resist. Conclusion: This study points out that nurses, associating

\footnotetext{
$1 \quad$ Artigo extraído da tese de doutorado "Os tempos e as relações de gênero: o cotidiano de enfermeiras e enfermeiros a partir do tempo de trabalho no hospital", apresentada à Escola Nacional de Saúde Pública. Apoio financeiro da Coordenação de Aperfeiçoamento de Pessoal de Nivel Superior (CAPES), Brasil.

2 Doutor pela Escola Nacional de Saúde Pública, Fiocruz. Professor Adjunto da Universidade Federal Fluminense. E-mail: auviprof@yahoo.com.br
} 
polychronic experiences with the presence of children, caring for the elderly and with the execution of household chores, refer to gender inequalities whose disorganization of time disproportionately affects the health themselves. To make specific comparisons and possible generalizations there is a need for future and extended investigations.

Keywords: uses of time; polychronicity; health; nurses; male nurses.

\section{Introdução}

Atualmente, pode-se observar que a sensação de aceleração dos ritmos e de escassez do tempo no dia a dia tem provocado nas pessoas uma necessidade de realizarem, de forma quase instantânea, várias coisas ao mesmo tempo. Esse modo contemporâneo de se relacionar com o próprio tempo pode provocar tensões e conflitos que interferem nos estilos de vida e, por sua vez, afetar a saúde.

Tais questões, ao serem olhadas a partir do campo de conhecimento das Ciências Sociais e dos recursos de compreensão histórica e cultural, possibilitam identificar o quanto os fatores de controle do tempo como o relógio e o calendário, permanecem influenciando os modos de organizar o dia a dia da vida (SILVA, 2010).

Além destes fatores usados para controlar e construir socialmente o tempo, crescentemente tem sido incorporado o uso desenfreado de tecnologias que provocam o encurtamento de distâncias geográficas, modificando a relação das pessoas com o próprio uso cotidiano do tempo (SENNETT, 2009; HARVEY, 2012).

Antes estagnada e predeterminada, a relação entre tempo e espaço passa a ser caracterizada como, processual, mutável e dinâmica. Encontram-se possibilidades de relações mais fluidas, e, portanto, mais adequadas aos fluxos do novo, às velocidades e aos imediatismos (SENNETT, 2009).

Recursos tecnológicos como telefones celulares, computadores e smartphones têm sido incorporados naturalmente nas relações da vida diária, modernizando os espaços, os tempos e as relações entre as pessoas. Assim, o avanço tecnológico, a conectividade plena e a constante realidade virtual podem ocorrer tanto para facilitar os modos de vida, como em muitas situações, para escravizar as pessoas. Pois, podem diminuir o tempo para a reprodução social caracterizando usos acelerados e constrangidos do tempo (HARVEY, 2012). 
Esse modo flexivel das relações com o tempo, cujas demandas extrapolam as paredes das esferas pública e privada, mobiliza as pessoas a fim de que permaneçam longo tempo à disposição do trabalho remunerado e ocupem grande parte do tempo pessoal e daquele destinado à família (BAUMAN, 2001; HARVEY, 2012).

Cada vez mais, numa perspectiva de aceleração, a urgência do tempo incentiva as pessoas a darem conta das inúmeras questões da vida contemporânea, na mesma quantidade de tempo anterior. Torna-se impossivel manter a separação dos espaços de produção e reprodução, caracterizada pelo predomínio e realização de várias atividades ao mesmo tempo.

Observar como as pessoas têm usado o próprio tempo de maneira metodológica, como ocorre nas pesquisas de Usos do Tempo, torna possivel registrar como vêm ocorrendo mudanças relacionadas a esse tempo socialmente construído na sociedade contemporânea (AGUIAR, 2010; CYRINO, 2011; HARVEY e SPINNEY, 2011; ROTENBERG, 2012; ROBINSON e GERSHUNY, 2013). Tais mudanças têm provocado nas pessoas a necessidade de desenvolver cada vez mais a realização de várias atividades ao mesmo tempo, ou seja, vivenciam a continuidade do tempo priorizando experiências que se aproximam da forma policrônica de se relacionar com o tempo (LINDQUIST e KAUFMAN-SCARBOROUGH, 2004; SOUITARIS e MAESTRO, 2010; KANTROWITZ, et al., 2012).

Assim, esse ensaio, apresentado a partir de uma pesquisa sobre os usos cotidianos do tempo de enfermeiras(os) numa metrópole no Estado do Rio de Janeiro - Brasil, tem como objetivo analisar em que medida as experiências de policronicidade afetam a saúde de enfermeiras(os) que trabalham em hospital.

\section{Método}

Estudo descritivo de abordagem qualitativa ancorado em pesquisas de Usos do Tempo (AGUIAR, 2010; CYRINO, 2011; HARVEY e SPINNEY, 2011; ROTENBERG, 2012; ROBINSON e GERSHUNY, 2013). Foi realizado a partir do cômputo individual do tempo diário, onde as/os participantes eram levados a refletirem sobre o próprio modo de organizar a dinâmica das atividades cotidianas. Assim, os fenômenos sociais atrelados aos usos do tempo, aqui apresentados, permitiram análises que destacaram aspectos significativos e subjetivos dos tem- 
pos a partir da mensuração objetiva (AGUIAR, 2010; ROTENBERG, 2012).

A pesquisa foi realizada na região metropolitana do Estado do Rio de Janeiro, num hospital de grande porte, durante os meses de janeiro e fevereiro de 2012. A escolha pelo local reflete a possibilidade de observar as experiências de usos policrônicos do tempo de enfermeiras e enfermeiros residentes em grandes cidades que trabalham em hospital. O que tornou possivel observar como a organização institucional que adota horários ininterruptos de trabalho, incluindo plantões noturnos e nos fins de semana, afeta de algum modo a vida cotidiana das/dos participantes do estudo.

As participações ocorreram a partir de entrevistas que foram realizadas com 42 enfermeiros (as), selecionados de um total de 93 participantes, no próprio local de trabalho. Após serem gravadas em meio digital foram posteriormente transcritas. As/Os participantes foram incluídos a partir de variáveis como: acúmulo de mais de um vínculo de trabalho, ocupação de cargos na gerência, presença de filhos pequenos ou idosos na família e realização de pós-graduação.

Foi usado um roteiro com perguntas abertas que abordavam temáticas como, conflitos relacionados à esfera doméstica e ao trabalho profissional, e organização do próprio tempo; sendo realizado teste piloto. Vale destacar que as perguntadas eram realizadas a partir de um movimento recordatório com as(os) participantes sobre os próprios registros quantitativos dos usos diários do tempo que foram coletados numa etapa complementar (parte de um projeto mais amplo) anterior às entrevistas (PEREIRA, 2015).

Para analisar as entrevistas oriundas desse processo optou-se pela técnica de análise temática, cuja intenção passa pela obtenção de informações que reflitam de modo expressivo o pensamento dos participantes do estudo sobre determinada temática (BARDIN, 2011). Duas categorias analíticas viabilizaram as reflexões: 1) Os tempos de enfermeiras(os) e o destaque para as experiências de policronicidade; e 2) A sobreposição de ações e a relação entre tempo e saúde.

conjunto de falas foi analisado sob influência de múltiplos referenciais teóricos, tendo destaque para os conceitos de monocronia e policronia. Deste modo, além de estar embasado em caminhos metodológicos das investigações de Usos do Tempo, este estudo encontra respaldo teórico em Edward Hall, ao destacar 
que as pessoas vivenciam a continuidade do tempo entre sistemas monocrônicos e policrônicos de tempo. Ou seja, por um lado o tempo é vivenciado de modo dividido onde as pessoas iniciam uma determinada atividade após o término de outra; e por outro, em que várias atividades são feitas ao mesmo tempo (LINDQUIST e KAUFMAN-SCARBOROUGH, 2004; SOUITARIS e MAESTRO, 2010; KANTROWITZ, et al., 2012).

A fim de respeitar todos os preceitos éticos da pesquisa com seres humanos, $\circ$ estudo foi submetido e aprovado pelo Comitê de Ética da Escola Nacional de Saúde Pública/Fiocruz, (Parecer $n^{0}$ 205/2011). Para manter o sigilo, os depoimentos foram identificados pela palavra enfermeira(o) seguida de números após cada fala.

\section{Resultados}

\section{1) Os tempos de enfermeiras(os) e o destaque para as experiências de policro- nicidade}

De forma interessante pode-se observar que grande parte das enfermeiras expressa de modo consentido, um predomínio de atividades realizadas ao mesmo tempo. Essa questão pode ser exemplificada a partir dos seguintes relatos:

Tenho uma vida muito louca $[\ldots]$ tudo ao mesmo tempo [...] por vezes é estressante... (enfermeira 08).

Sempre tomei conta dos filhos trabalhando... pelo telefone, monitorando. [...] Administro tudo numa boa até mesmo nas horas dos grandes problemas... (enfermeira 60).

Já a maioria dos enfermeiros refere que a sobreposição de ações tende a se afastar do cotidiano de suas vidas. Vide a fala que exemplifica essa resistência:

Nunca faço várias coisas ao mesmo tempo... [...] acho horrivel... acho isso uma atitude patológica... organizo o meu tempo de modo que eu possa dar atenção exclusiva para o que estou me focando... (enfermeiro 68).

No entanto, a seguir encontra-se discurso como o do enfermeiro 01, que por outro lado mostra a possibilidade de que a vida contemporânea também se mostra acelerada e provoca uma determinada coerção para que também os homens estejam realizando várias coisas ao mesmo tempo. 
Você enfrenta aquele engarrafamento danado e atende telefone no engarrafamento e já chega em casa estressado e já pensa no outro dia no que você vai fazer... e que se sente invadido... então... depois que inventaram o celular... (enfermeiro 01).

A diferença entre o grupo de enfermeiras e enfermeiros pode se tornar mais evidente através de discursos que associam as experiências de policronicidade à presença de filhos e à execução de atividades domésticas. As enfermeiras que têm filhos pequenos descrevem episódios que remetem às sobreposições de atividades e à uma determinada (des)organização do tempo. Essas situações se refletem nas falas da maioria das entrevistadas permitindo o destaque para os sucessivos trabalhos de disponibilidade integral, independente do horário ou do dia da semana.

Veja o relato de uma enfermeira que exemplifica a contínua necessidade de realizar várias atividades durante um período limitado, caracterizando controles de horários e um determinado milagre da multiplicação dos tempos.

Tem que levar o C. no psicólogo, na fono... tem que cuidar da casa... sempre uma desculpa pra não estar fazendo o cuidado de mim isolado [...] ai depois vem aquele cansaço... (enfermeira 61).

Entender que existam diferenças entre mulheres e homens quanto às experiências de usos policrônicos do tempo, não impede aceitar que os homens também relatem essas situações. Mesmo que em minoria, existem enfermeiros com filhos menores que apresentam usos do tempo similares aos das enfermeiras nas mesmas condições, ou seja, policronia no âmbito privado. Ao confrontar as impressões os entrevistados a seguir mencionam experiências de sobreposição de cuidados de outros e atividades domésticas que estão presentes na vida em família.

Sobreponho atividades domésticas com cuidar de outros... acho importante... colocar a mesa pra minhas filhas... é uma atividade doméstica, mas é um momento que eu tenho de relação $[\ldots]$ a coisa do dever de casa $[. .$.$] até momento de lazer...$ (enfermeiro 39).

Consigo ver uma comida pra uma criança... enquanto a comida esquenta eu consigo lavar uma louça... enquanto come eu já vou lá e tomo um banho [...] consigo articular isso tudo praticamente ao mesmo tempo [...] você fica pra lá e pra cá com dois empregos, com atividade doméstica, com os compromissos do dia a dia... (enfermeiro 64). 
Vale destacar que mesmo diante de tais transições, essas situações se apresentam de modo atípico com o grupo masculino e predominante com o grupo feminino. No entanto, as experiências de policronicidade que mais se apresentaram valorizadas nas falas dos enfermeiros foram aquelas predominantes nos espaços do trabalho remunerado no hospital.

Assim, ressalta-se que dependendo do tempo/espaço em que o enfermeiro se encontra, isto é, quando está no âmbito privado não percebe problema em fazer várias coisas, pois parece conseguir maior controle do próprio tempo a partir do poder individual de delimitar tempo para si.

Em casa eu levo isso numa boa... porque sei que se não conseguir fazer aquilo naquele momento, pode ficar pra depois [...] é diferente com o paciente... você tem que fazer... tem coisa que não dá pra esperar... você tem que tomar providência... [...] quando tem muitas coisas pra fazer ao mesmo tempo... às vezes estressa... (enfermeiro 73).

Desta forma, quando se encontram no espaço público têm dificuldades, pois existe maior controle do tempo institucionalmente cronometrado, imprimindo a necessidade de se relacionarem com as experiências de policronicidade.

2) A sobreposição de ações e a relação entre tempo e saúde

Quanto à possibilidade de relação entre o tempo e a saúde, vale chamar a atenção que usos desiguais dos tempos afetam de modo diferenciado os estilos de vida e as condições de saúde de mulheres e homens. E no caso específico das enfermeiras, que naturalizam a possibilidade de realizar inúmeras atividades ao mesmo tempo e acumular variadas responsabilidades no dia a dia, são elas que mais demonstraram estarem com a saúde afetada.

Tem dia que eu acho que vou ficar louca... fico sobrecarregada... sono prejudicado... extremamente irritada, muito estressada, cansada [...] vejo que a culpa também é minha... (enfermeira 05).

Minha vida é um pouco tumultuada, pelo trabalho e familia grande... ao mesmo tempo em que eu estou cuidando de mim estou cuidando dos outros... fico assoberbada, cansada, nervosa... (enfermeira 60).

Você tem que atender as suas necessidades, as necessidades do marido (enfermeiro 39), as necessidades das filhas, da mãe, do trabalho, da sogra... acho que é cumulativo... por isso acho que abala a saúde... o meu emocional... (enfermeira 69). 
Os relatos acima mostram o quanto as experiências de policronicidade têm sido incorporadas de maneira que vão se sobrepondo entre realização direta de cuidados dos filhos, atividades domésticas e trabalho remunerado no hospital, afetando diretamente a saúde.

Hoje eu estou muito cansada... já saio do trabalho aqui no hospital pensando o que eu tenho que fazer em casa [...] então aquilo vai me angustiando [...] nenhum momento de pausa pra mim [...] aí vai dando aquelas dores na cervical... dor de cabeça... e você já está naquele topo de cansaço... (enfermeira 53).

Eu já estou até com dor na lombar... isso já esta afetando... estresse... eu sou uma pessoa que sabe lidar com algumas coisas... agora tem situações que estou andando estressado... não tenho paciência... estou percebendo que isso afeta diretamente a saúde... (enfermeiro 11).

acúmulo consentido de funções e papéis que estruturam relações de simbiose entre as esferas casa - trabalho remunerado / trabalho doméstico - vida hospitalar, e o menor tempo disponivel para si, tende a resultar em menores possibilidades de negociação para o cuidado com a própria saúde, tornando-se evidente que a convivência com tensões e conflitos persistentes, afeta de alguma maneira a saúde física e mental.

Cabe apontar que a partir da realização desse estudo foi possivel identificar algumas limitações como resistência de participação de alguns profissionais mediante possibilidade exposição da vida privada e tímida exploração de análises sobre tempo-saúde destes(as) profissionais com destaque para as relações diretas no processo de trabalho hierárquico, disciplinador e tradicional do hospital.

\section{Discussão}

Um dos problemas mais dificeis que os pesquisadores que investigam os usos do tempo podem enfrentar é a forma exata que as pessoas registram as atividades cotidianas, sobretudo quando diz respeito as situações que ocorrem ao mesmo tempo, mediante o dinamismo da vida (SCHULZ e GRUNOW, 2012). A caracterização dessas atividades realizadas ao mesmo tempo reflete àquelas existentes no dia a dia de maneira sobreposta, constrangendo os tempos.

Por sua coerção, o tempo construído socialmente provoca conflitos quando as pessoas não conseguem dar conta de viver conforme os moldes desses tempos, 
sobretudo quando se apresentam acelerados e vividos sob uma determinada conectividade plena, como tem ocorrido na sociedade contemporânea (SENNETT, 2009; HARVEY, 2012).

Ao enfatizar o aspecto qualitativo, alguns estudos (LINDQUIST e KAUFMAN-SCARBOROUGH, 2004; SOUITARIS e MAESTRO, 2010; KANTROWITZ, et al., 2012) contribuem para ampliar análises sobre a possibilidade de homens e mulheres lidarem de maneira diferente com a realização de várias coisas ao mesmo tempo. Desta maneira, as situações de policronicidade estiveram mais presentes nos discursos das enfermeiras, cujos tempos são caracterizados pela possibilidade das pessoas realizarem mais de uma tarefa ao mesmo tempo, do que nas falas dos enfermeiros, que contextualizam diminuição dessas experiências e posicionamentos que os afastam do exercício de realizarem várias atividades ao mesmo tempo.

A enfermeira 60, ao dizer que ao longo da vida tomou conta / monitorou os filhos pelo telefone, consegue exemplificar o quanto o uso contemporâneo de tecnologias pode encurtar distâncias, provocar imediatismos e (des)organizar o tempo cotidiano (SENNETT, 2009; HARVEY, 2012).

Não quer dizer que essas características estejam polarizadas, onde os posicionamentos estejam estanques. Vide a fala do enfermeiro 01 destacando convivência com o uso do celular de modo constante que atravessa até mesmo os espaços e tempos de deslocamentos. Essa ideia de espaços de fluxos encontrada em Zygmunt Bauman (2001) caracteriza os acontecimentos que não aguardam a chegada em outros locais para que aconteçam. Esse tempo em trânsito caracteriza a existência de policronicidade vivenciada tanto por homens quanto por mulheres.

Assim, por um lado, pode-se observar que também existiram enfermeiras que se aproximaram de usos monocrônicos do tempo e por outro, enfermeiros que se permitiram relatos de experiências policrônicas. $O$ que pode ser destacado no caso desse estudo, é que em relação à policronicidade, por parte da maioria dos homens existe um movimento de resistência e por parte da maioria das mulheres uma determinada aquiescência. $\bigcirc$ que possibilitou identificar relatos apontando que a saúde das mulheres, sobretudo a mental, tem sido mais afetada.

Talvez, priorizar justificativas que apenas levem em consideração predisposi- 
ções femininas para experiências policrônicas e associá-las a um fazer constante e não refletido, nem mesmo questionado, leva várias enfermeiras a incorporarem discursos que demonstram tendências em naturalizar o acúmulo persistente e progressivo de funções para as mulheres e a realização de uma atividade de cada vez para os homens.

Desta forma, os desdobramentos provenientes dessa situação também oportunizam refletir sobre conflitos sinalizados por algumas enfermeiras, com relação à divisão desigual do trabalho doméstico e ao acúmulo de funções realizadas gratuitamente no âmbito da vida privada (ROTENBERG, 2012). O exemplo das enfermeiras 05 e 60 tornou explícito o quanto a atenção para os outros era incorporada progressivamente em detrimento de disponibilidade para si, gerando sentimentos de culpa e autocobranças, além de conflitos relacionados aos usos constrangidos dos tempos (PEREIRA, ROTENBERG e OLIVEIRA, 2013).

Em geral, as mulheres se ocupam das atividades domésticas e cuidados com os filhos, imerso em sobrecargas de funções que se conflitam entre o tempo usado no trabalho remunerado e o cumprimento das demais exigências sociais (OFFER e SCHNEIDER, 2011).

O próprio trabalho doméstico, sucessivo e interminável, demanda uma ocupação diferenciada de tempos, em que na maioria das vezes, a sobrecarga direcionada às mulheres, nesse caso às enfermeiras, gera uma desproporção entre os tempos usados para si e para os outros em meio a policronicidade cotidiana.

Neste contexto, o destaque para a policronicidade existente no âmbito doméstico, maior vivenciada pelas enfermeiras, além de exigir iniciativas sob pressão e testes de paciência, podem expressar sentimentos de insatisfação, maior sensação de peso, sobrecarga e estresse diante da carga total de trabalho (OFFER e SCHNEIDER, 2011), o que afeta diretamente o dia a dia das enfermeiras desse estudo.

A correlação entre tempo corrido/falta de tempo e processo saúde-doença também se encontra presente no cotidiano dos enfermeiros, isto é, vida acelerada e tensões diárias, contribuem de modo significativo para que refiram pouco tempo para si e inclusive falta de tempo para cuidar da própria saúde.

No entanto, a diferença aqui existente, denota que o acúmulo e/ou sobreposição de ações realizadas pelos enfermeiros encontram-se focalizados ao âmbito 
profissional hospitalar, a partir do grande tempo de trabalho remunerado com seus horários atípicos que perfazem o período noturno e os finais de semana. Não quer dizer que as enfermeiras estejam menos afetadas pela dinâmica da vida hospitalar, mas que além desses desencontros provocados pelos tempos institucionais, elas ainda se permitem envolver mais com o âmbito da vida privada.

Realizar atividades sobrepostas e frequentes caracteriza o quanto a vida de alguns enfermeiros, e principalmente enfermeiras, têm sido de rotinas corridas, mecânicas e permeadas por imprevistos. Assim, torna-se importante destacar que em alguma medida essa aceleração afeta os usos do tempo e a própria saúde.

Assim, mesmo que tenham sido observadas empiricamente desigualdades relacionadas ao gênero, vale destacar que o fato de ter vida corrida entre trabalhos, uso intensificado de tecnologias de comunicação e falta de tempo para as demandas pessoais, torna possivel identificar pistas de como esses eventos de policronicidade existentes num cotidiano acelerado interferem direta e especificamente na saúde.

\section{Conclusão}

As análises realizadas até o momento, a respeito das experiências policrônicas relatadas por enfermeiras e enfermeiros deram margem para aprofundar reflexões que dizem respeito às relações entre tempo e saúde.

Pode-se observar que as enfermeiras parecem referir mais conflitos e tensões quando as experiências de policronicidade ocorrem no âmbito da vida privada e os enfermeiros mais incômodos quando ocorrem nos espaços da instituição hospitalar. Contudo, tanto enfermeiras quanto enfermeiros parecem e percebem-se afetados por essas formas de relação com os tempos acelerados e instantâneos.

Assim, os enfermeiros, mesmo surgindo relatos de policronicidade direcionados ao âmbito da vida pública / profissional, apresentam tendências de preservar um pouco mais de tempo para si e realizar uma atividade de cada vez. As enfermeiras expressaram maiores níveis de desgastes mediante experiências policrônicas de usos do tempo, com destaque para o âmbito da vida privada.

Deste modo, quando se trata de vida corrida entre os tempos cotidianos a partir do trabalho no hospital, os desdobramentos provenientes das experiências de policronicidade que provocam conflitos e tensões, caracterizam não só 
desigualdades de gênero, entre os tempos ocupados consigo e com os outros no cotidiano da vida, como também exemplificam de maneira expressiva os rebatimentos nas condições de saúde física e mental.

Referências

AGUIAR, N. F. Metodologias para o levantamento do uso do tempo na vida cotidiana no Brasil. Revista Econômica, v.12, n.1, 2010.

BARDIN, L. Análise de Conteúdo. Edição revista e actualizada. Lisboa: Edições 70, Lda. 2011.

BAUMAN, Z. Modernidade Líquida. Jorge Zahar, 2001.

CYRINO, R. A gestão do trabalho doméstico entre mulheres executivas: um exemplo de combinação de dados de uma pesquisa de Usos do Tempo com metodologia qualitativa. Política e Trabalho, v.34, 2011.

HARVEY, D. Condição Pós-moderna. Uma pesquisa sobre as origens da mudança cultural. Edições Loyola, 2012.

HARVEY, A.; SPINNEY, J. Activity and contextual codes - Implications for time-use coding schemes. Electronic International Journal of Time Use Research, v.8, n.1, 2011.

KANTROWITZ, T. M. et al. Time Is Money: Polychronicity as a Predictor of Performance Across Job Levels. Human Performance, v.25, 2012.

LINDQUIST, J. D.; KAUFMAN-SCARBOROUGH, C. F. Polychronic tendency analysis: a new approach to understanding women's shopping behaviors. Journal of Consumer Marketing, v.21, n.5, 2004.

OFFER, S.; SCHNEIDER, B. Revisiting the Gender Gap in Time-Use Patterns: Multitasking and Well-Being among Mothers and Fathers in Dual-Earner Families. American Sociological Review, v.76, n.6, 2011.

PEREIRA, A. V. O cotidiano de enfermeiras e enfermeiros: relações de gênero, a partir do tempo no hospital. Rev. Latino-Am. Enfermagem, v.23, n.5, 2015.

PEREIRA, A. V.; ROTENBERG, L.; OLIVEIRA, S. S. Relações de Gênero e Interdependências: reflexões a partir de mudanças na configuração hospitalar. História, Ciências, Saúde - Manguinhos, v.20, n.3, 2013.

ROBINSON, J. P.; GERSHUNY, J. Visualizing multinational daily life via multidimensional scaling (MDS). Electronic International Journal of Time Use Research, v.10, n.1, 2013. 
ROTENBERG, L. Relações de gênero e gestão dos tempos - a articulação entre o trabalho profissional e doméstico em equipes de enfermagem no Brasil. Laboreal, v.8, n.1, 2012.

SCHULZ, F.; GRUNOW, D. Comparing Diary and Survey Estimates on Time Use. European Sociological Review, v.28, n.5, 2012.

SENNETT, R. A corrosão do caráter: as consequências pessoais do trabalho no novo capitalismo. Record, 2009.

SILVA, N. L. M. O tempo social de Norbert Elias: uma proposta de superação ao conhecimento dicotômico do tempo. Revista de Humanidades MNEME, v.11, n.27, 2010.

SOUITARIS, V.; MAESTRO, B. M. M. Polychronicity in top management teams: The impact on strategic decision processes and performance of new technology ventures. Strategic Management Journal, v.31, n.6, 2010.

Recebido em maio de 2018

Aceito para publicação em junho de 2018 